that Geber acquired some of his notions of chemistry from Egypt.

Several MSS., purporting to contain the writings of Geber, exist in various libranes in Europe; these were translated into Latin as early as the year 1 529, and into English in 1678 . We have reason to believe that the Latin translation was faithfully done, if the Arabic text be not corrupt. The work consists of four treatises:- $(\alpha)$ Of the search for Perfection, $(\beta)$ Of the Sum of Perfection, $(\gamma)$ Of the Invention of Verity, and $(\delta)$ Of Furnaces. Geber was acquainted with the seven metals known to the ancients, and he regarded gold, silver, copper, iron, tin, and lead, as compounds of mercury with sulphur in different proportions. Gold and silver are the most perfect metals, and are composed of the purest mercury and sulphur; the other metals consist of less pure mercury and sulphur, but may be converted into gold and silver by purifying their constituents, and uniting them in different proportions. He also describes various chemical substances, among others the following. The carbonates of potash and soda were known to Geber, and were procured from the ashes of plants. Caustic soda was procured from the carbonate by heating its solution with quicklime, as in the present day. Common salt was purified by ignition, solution, and filtration, and the solution was afterwards evaporated, and the salt crystallised out. Nitrate of potash, or saltpetre, and chloride of ammonium, or sal ammoniac, were apparently common in Geber's time; as also were alum, borax, and green copperas, or protosulphate of iron. Geber procured nitric acid by distilling copperas, saltpetre, and alum, and he used the acid for dissolving silver, and when mixed with sal ammoniac for dissolving gold. He obtained nitrate of silver in the form of crystals, and noticed their fusibility. Various compounds of mercury are described, among others corrosive sublimate or chloride of mercury, cinnabar or sulphide of mercury, and the red oxide of mercury, in which, mearly ten centuries later, oxygen gas was discovered by Dr. Priestley. Geber also obtained sulphuric acid by distilling alum. He appears to have been acquainted with the various processes of distlllation, sublimation, calcmation, filtration, and many others ; indeed, with almost all the processes practised by his successors during the succeeding eight or nine centuries.

It is probable that some of the processes described by Geber were worked out in the medical schools of Arabia, and were known shorily before bis time; yet he was himself a patient worker, and often intersperses his descriptions of substances and processes with remarks on the method of experimenting, and the mode of thought most suitable for the studies which he describes. He has often been called the "Founder of Chemistry ;" at least his works are the earliest with which we are acquainted, and he was venerated as Master alike by the alchemists and chemists of the Middle Ages.

Geber appears to have been acquainted with many chemical appliances. In the earliest translations of his works we find figures of various furnaces and forms of distillatory apparatus; one of them, not unlike a still now in use, is represented above. The greater number of vessels described and figured by Baptiste Porta in his treatise De Distillationibus, published in 1609 , are to be found in the first Latin translations of the works of Geber. G. F. RODWELL

\section{THE ARCTIC EXPEDITION}

$T H E$ following is the text of the reply of the Grovernment to the deputation which recently had an interview with Mr. Lowe and Mr. Goschen :-

"II, Downing Street.

"Dear Sir Henry Rawlinson,-Mr. Goschen and I have carefully considered the documents which you have laid before us with regard to the proposed Arctic Expedition.

"We do not find in them anything which shows that there is any pressing reason why the expedition should be sent this year.

"We give no opinion as to the expediency of such an expedition at a future time, but we are clearly of opinion that it would not be right to send out a second scientific expedition precisely at the moment when the public revenue has to bear the main burden of the expenses of the operations intrusted to the Challenger.

"I believe it has been erroneously stated that the
Challenger Expedition involves very little expense. That is not so. The cost has already been considerable, and nothing has been spared to insure success; there will further be an additional annual outlay for three years.

"Under these circumstances, we regret that we cannot recommend the sending an exploring party to the Arctic Ocean as a Government enterprise this year.

$$
\begin{aligned}
& \text { "Believe me, yours very truly, } \\
& \text { "ROBERT LowE. }
\end{aligned}
$$$$
\text { "Sir Henry C. Rawlinson, K.C.B." }
$$

It is clear, we take it from this, that it only remains for the men of science to make out their case, and we believe that the Arctic Committee are fully alive to this. The Daily News in a leader has indicated what we had already ventured to suggest as the weak point of the appeal, namely that it was incomplete, and that many men of science knew nothing of the proposed expedition. But in doing this we had no intention to cast a slur upon the Geographical Society; on the contrary we think that that Society's action in this matter is one which the Royal Society could now follow with the greatest advantage to science, and which we hope it will follow.

In I 865 the Geographical Society begged the Royal Society to take the lead in this matter, but the Royal Society Council declined. In 1872 the Geographical Society again entreated the Royal Society to take the matter up, but again received a chilling reply to the effect that the Royal Society Council would be prepared to give advice when applied to by the Government.

The Geographical Society then did the next best thing. It applied to other leading scientific societies, and to some few scientific men for statements of results to be derived from Arctic exploration. These it received and laid before Government, without giving any undue prominence to purely geographical results.

It is clear, therefore, that it is now the duty of the Royal Society and the other societies at once to add their influence to the movement; let a joint committee be formed to report, if need be, to the various councils. In this way the knowledge posessed by all specialists ought to be made available for the common good, so that a complete statement may be forwarded to the Government in the summer to enable the officers of the expedition to be appointed in time to avail themselves of special training.

\section{NOTES}

THE recent fusion of the Ethnological and Anthropological Societies under the designation of "the Anthropological Institute of Great Britain and Ireland," not only did good service to science but has financially proved thus far so successful that the Report of the Council for 1872 , to be presented to the members next Tuesday evening at the annual meeting, announces a handsome surplus income applicable to the reduction of liabilities incurred in former years. In this promising condition of financial prosperity it is all the more to be deplored that a serious dissension has arisen in the Council in reference to the nomination of a successor to Sir John Lubbock, who, to the universal regret of the members, vacates the presidential chair, under the pressure of parliamentary and other engagements. Touching this matter we have received a copy of a printed statement signed by Mr. Harris and seven other members of Council, which alleges that at a Council Meeting, held on the I th of last month, Dr. Charnock was placed on the House List for 1873, but that at a succeeding Council Meeting of January 7 , this nomination was rescinded and the House List recast with the substitution of Professor Busk as President in the place of Dr. Charnock. This recasting of the List is made a matter of protest, and the members of the Institute, with whom the final decision rests, are appealed to. $\ldots$ We need hardly remark that 